\title{
CORRIGENDUM
}

\section{Delimitation and description of the immature stages of a pollinating fig wasp, Ceratosolen solmsi marchali Mayr (Hymenoptera: Agaonidae) - CORRIGENDUM}

\section{Ling-Yi Jia, Jin-Hua Xiao, Li-Ming Niu, Guang-Chang Ma, Yue-Guan Fu, Derek W. Dunn and Da-Wei Huang}

doi:10.1017/S0007485313000606, Published by Cambridge University Press, 29 November 2013.

The authors apologise for errors in the original version of this article. It contained errors in the positions of Figures 3, 4, 7, 8 and 9. The correct positions are listed as follows:

Figure 3 should move to the position of Figure 8; Figure 4 to Figure 9; Figure 7 to Figure 3; Figure 8 to Figure 4; and Figure 9 to Figure 7.

Please see below the figures with their correct captions.
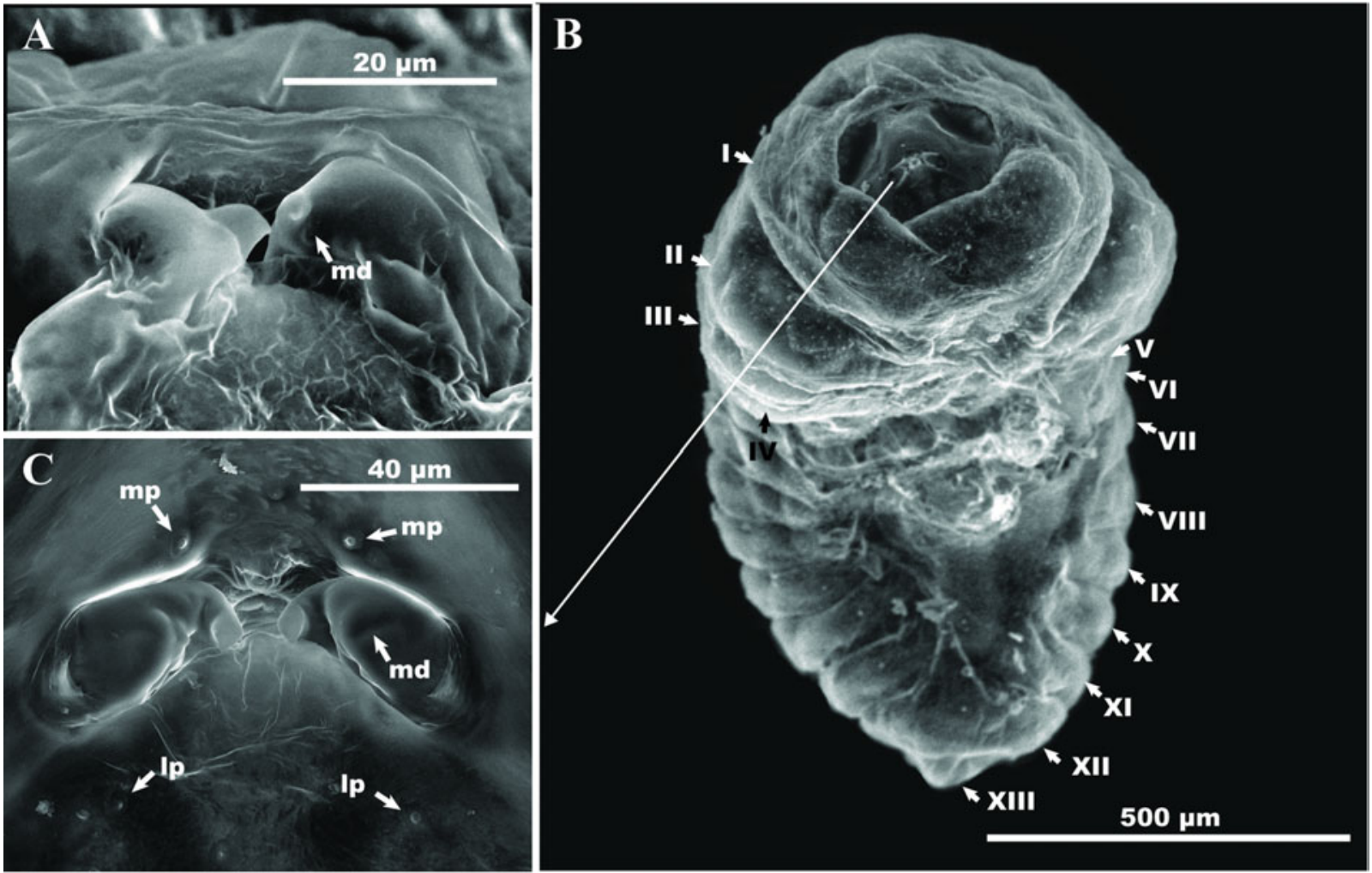

Fig. 3. Third- and fourth-instar larva (A) Mouthparts of third-instar larva (13th day post-oviposition), showing sharply edentate mandibles. (B) Ventral view of fourth-instar larva (17th day post-oviposition). (C) Enlarged view of mouthparts of fourth-instar larva (md: mandible; mp: maxillary palp; lp: labial palp). Thirteen body segments (I-XIII) were illustrated in B. 


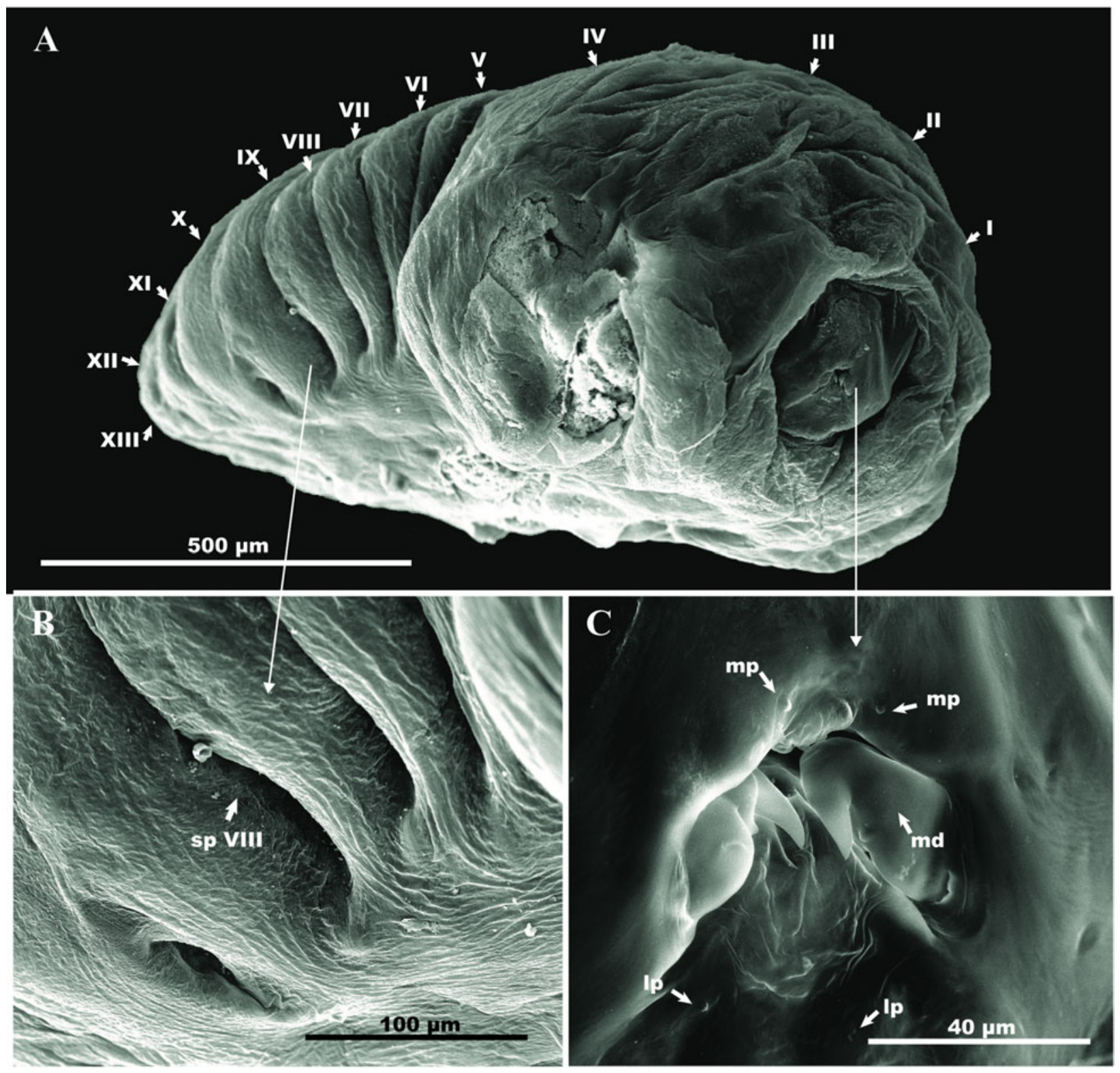

Fig. 4. Final-instar larva under SEM: (A) Lateral view of fifth-instar larva (19th day post-oviposition). (B) Enlarged view of spiracle, showing the largest spiracle (spVIII). (C) Enlarged view of mouthparts (md: mandible; mp: maxillary palp; lp: labial palp). Thirteen body segments (I-XIII) were illustrated in A. 

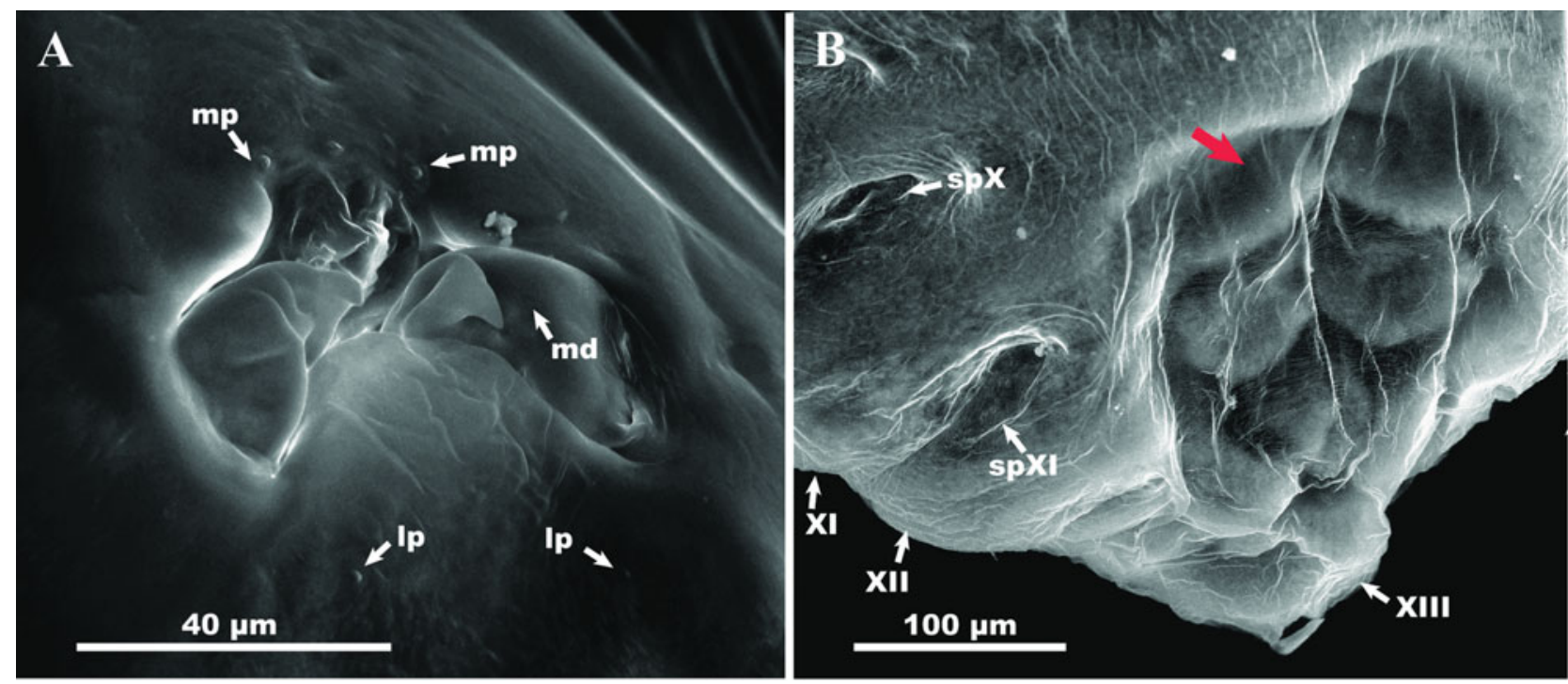

Fig. 7. Prepupa of C. solmsi marchali under SEM: (A) Mandibles of prepupa (21th day post-oviposition), (md: mandible; mp: maxillary palp; lp: labial palp). (B) Ventral view of metasomal segmentation of pupa under larval skin, showing the depressed area on abdomen (red arrow), several metasomal segments (XI, XII, XIII), and the last two spiracles (spX and spXI).
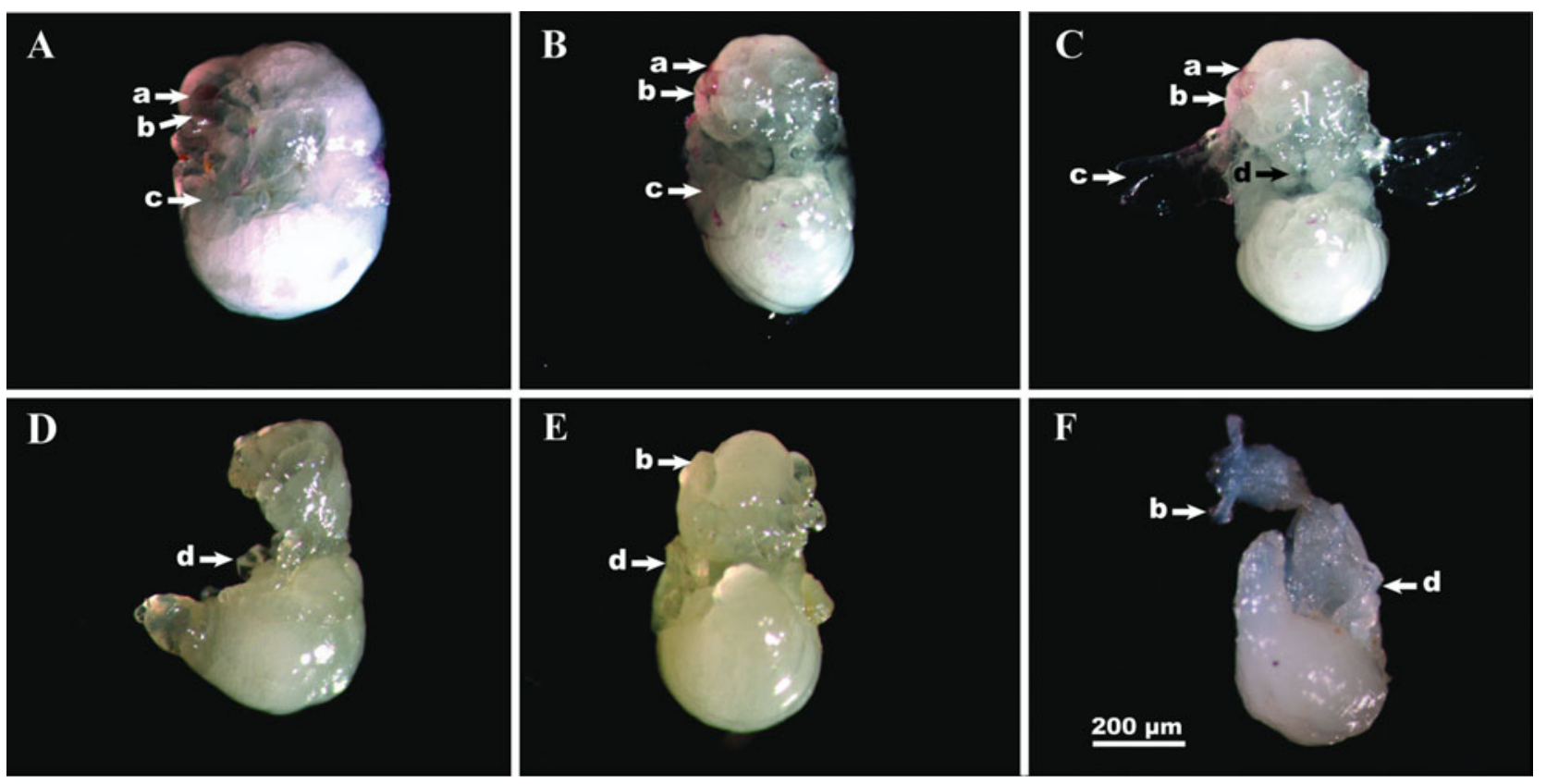

Fig. 8. Primary pupa of both sexes, showing the compound eyes of female (a), antennae (b), wing buds of female (c), and legs (d): (A, B, C) Primary pupa of female (21st day post-oviposition) with pink eye spots and longer antennae. Wing buds in $\mathrm{C}$ were outspreaded artificially. (D, E, F) Primary pupa of male (21st day post-oviposition). 

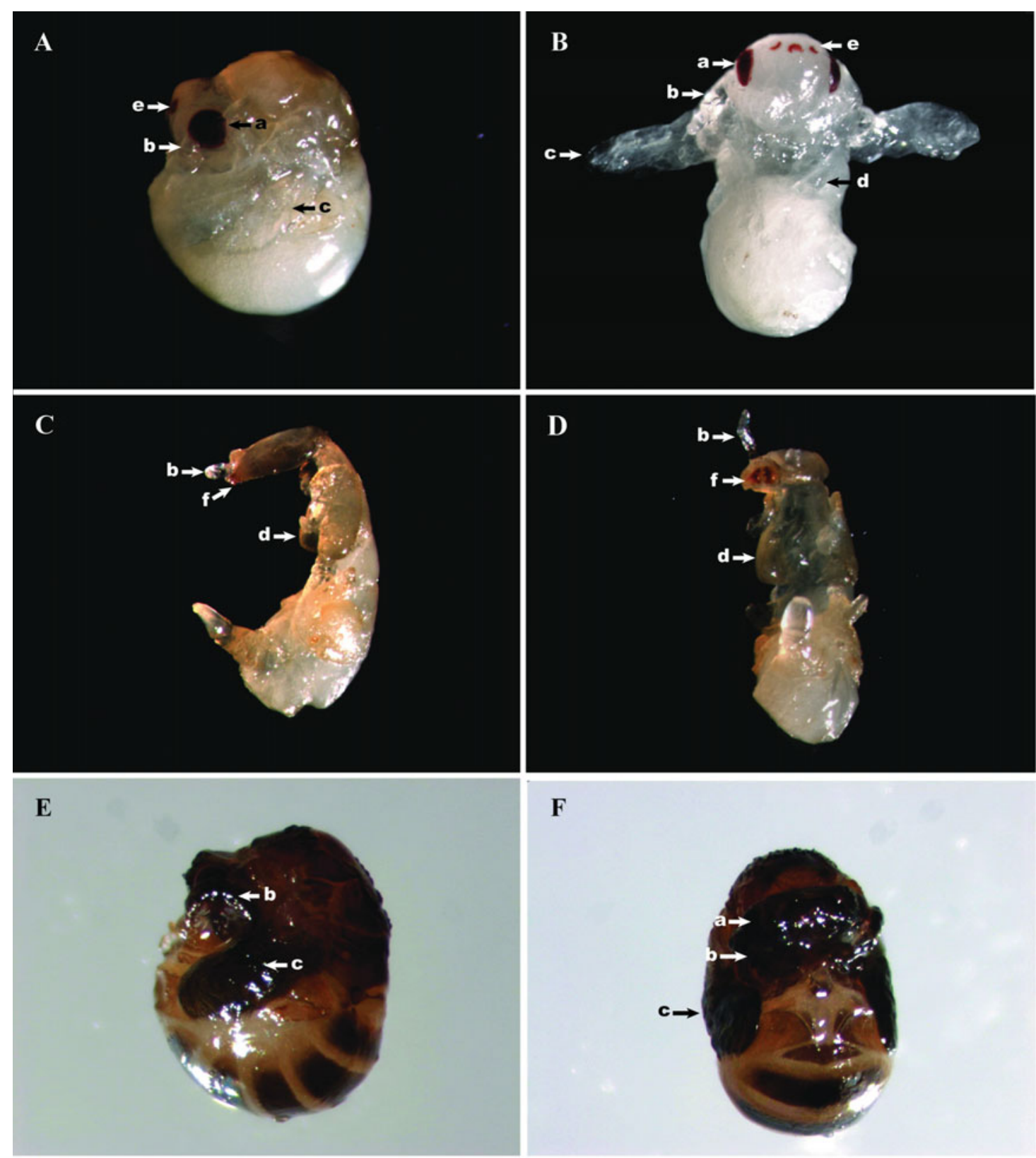

$\mathbf{F}$
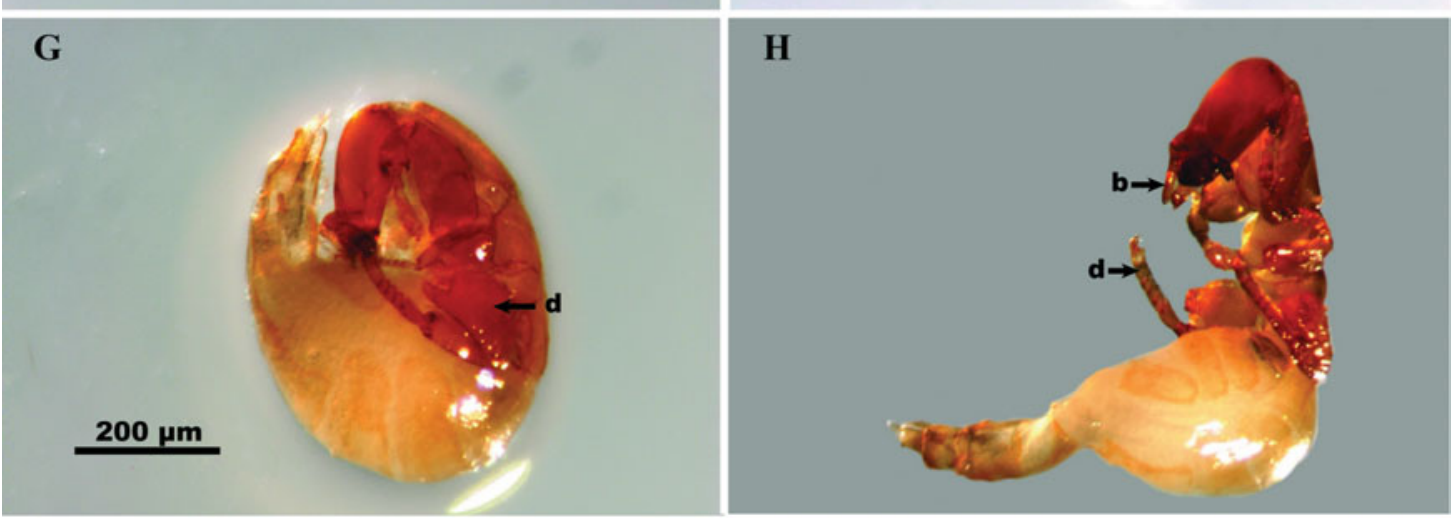

Fig. 9. Intermediate pupa and mature pupa of both sexes, showing the compound eyes of female (a), antennae (b), wing buds of female (c), legs (d), ocelli of female (e), and mouthparts of male (f): (A, B) Lateral and ventral view of intermediate pupa of female (25th day postoviposition). Wing buds in (B) were outspreaded artificially. (C, D) Intermediate pupa of male (25th day post-oviposition). (E, F) Mature pupa of female (27th day post-oviposition) with black wing pads. (G, H) Mature pupa of male (27th day post-oviposition). 


\section{Reference}

Jia, L.-Y., Xiao, J.-H., Niu, L.-M., Ma, G.-C., Fu, Y.-G., Dunn, D.W. \& Huang, D.-W. Delimitation and description of the immature stages of a pollinating fig wasp, Ceratosolen solmsi marchali Mayr (Hymenoptera: Agaonidae). Bulletin of Entomological Research. Published by Cambridge University Press, 29 November 2013. doi:10.1017/S0007485313000606. 